\title{
Allozyme diversity in Leavenworthia populations with different inbreeding levels
}

\author{
D. CHARLESWORTH* \& Z. YANG \\ Department of Ecology and Evolution, University of Chicago, 1101 E 57th St., Chicago, IL 60637, U.S.A.
}

\begin{abstract}
Levels of allozyme diversity were studied in five species of the annual plant genus Leavenworthia. The breeding systems of the populations were also characterized in terms of measures of autogamous seed-set and self-fertility. The populations that appeared more inbreeding by these criteria also tended to have lower within-population gene diversity $\left(H_{\mathrm{S}}\right)$ values, but there was nevertheless considerable allozyme variability in two of the four sets of inbred populations studied. Comparing the outcrosser L. stylosa and the related inbreeders L. uniflora and L. torulosa the reduction in diversity associated with inbreeding was very high, as no variants were seen within populations of the inbreeders. In L. crassa and L. alabamica, the reduction was lower, but correcting for the fact that this comparison is over less extreme selfing rate differences, it is estimated that the difference between extreme inbreeding and outcrossing populations of $L$. crassa considerably exceeds twofold. These results are compared with published studies within closely related taxa with different inbreeding levels. The effect of inbreeding on allozyme diversity is consistently larger than has been estimated from comparisons of unrelated species.
\end{abstract}

Keyw ords: allozymes, genetic diversity, inbreeding, Leavenworthia.

\section{Introduction}

An important problem in population genetics is the maintenance of genetic variability within and between natural and other populations (e.g. Kimura, 1983; Kreitman, 1991). Differences in diversity patterns, such as the lowered neutral DNA diversity at loci in regions of unusually low recombination in Drosophila species, may illuminate factors that play important roles in determining genetic variability (e.g. Langley, 1990; Begun \& Aquadro, 1992). One situation in which diversity is often low is in inbreeding populations (Schoen \& Brown, 1991; Jarne \& Staedler, 1995; Hamrick \& Godt, 1996), and it is important to understand what causes this highly repeatable pattern.

It is sometimes stated that inbreeding does not lead to loss of genetic diversity in species but merely redistributes it between individuals and between populations (e.g. Fenster \& Ritland, 1992), but this is true only in the evolutionary short-term. Over evolutionary time, several factors operate in inbreeding populations that may reduce neutral

\footnotetext{
*Correspondence and present address: Institute of Cell, Animal and Population Biology (ICAPB), University of Edinburgh, Ashworth Laboratory, King's Buildings, W. Mains Rd., Edinburgh EH9 3JT, U.K. E-mail: deborah.charlesworth@ed.ac.uk
}

diversity compared with outbreeders. In very inbred populations, each individual carries two identical genomes (i.e. is highly homozygous). This reduces effective population sizes $\left(N_{\mathrm{e}}\right.$ values; complete inbreeding halves $N_{\mathrm{e}}$, see Brown, 1979 and Pollak, 1987). Under the classical theory of neutral molecular evolution, allelic diversity depends on $N_{\mathrm{e}}$ values (Kimura, 1983). A very inbreeding population thus behaves similarly to one of half its actual size, as far as molecular variation is concerned, and is expected to have half the neutral diversity levels of otherwise similar outcrossing populations. In addition, bottlenecks in population size may be more extreme in inbreeders (Schoen \& Brown, 1991), in which a single seed can found a new population. Also, the lack of effective recombination (i.e. the rarity of production of recombinant genotypes) in inbreeding populations may lead to phenomena similar to those seen in low-recombination regions of genomes (see above). This increases the importance of selective sweeps of advantageous mutations (Hedrick, 1980) and 'background selection' caused by elimination of deleterious mutations, which also leads to the evolution of lower levels of neutral diversity in such populations (reviewed in Charlesworth et al., 1993).

In comparing genetic diversity from populations differing in their levels of inbreeding, the effect of 
breeding system on diversity should ideally be studied in a set of related taxa differing in little else than the breeding system variations that are the focus of interest. Plants offer opportunities to make such comparisons. An effect of breeding system differences on allozyme diversity is quite well-documented in plants (Schoen \& Brown, 1991; Hamrick \& Godt, 1996), and animals (Jarne \& Staedler, 1995), but the data are not at present completely satisfactory as there have been few paired comparisons involving inbreeder/outbreeder species that are similar in their other characteristics, such as life history (Wolff, 1991). In the few studies comparing species within genera, however, the patterns appear robust (Charlesworth et al., 1997).

Allozyme variants may be selectively maintained (e.g. Hudson et al., 1994), so theories for neutral differences may not apply to them. Loci with variants maintained by heterozygote advantage are expected to lose diversity under inbreeding and, at high selfing rates, such polymorphism is unlikely to be maintained (Kimura \& Ohta, 1971). It is, nevertheless, worthwhile to study them, as they offer a relatively technically simple source of diversity information, and the contrast to DNA sequence data can be valuable (Karl \& Avise, 1992; Pogson \& Zouros, 1994). Some data on plants of the mustard genus, Leavenworthia, are reported here. This genus is a classic example of breeding system evolution (Lloyd, 1965; Solbrig \& Rollins, 1977; Lyons \& Antonovics 1991). The general aim of the work was to estimate genetic diversity from populations with different levels of inbreeding, to test whether inbreeding populations have lower diversity than outbreeding ones, and to estimate the magnitude of any such difference, for comparison with the results on DNA sequence diversity (Liu et al., 1998).

\section{Materials and methods}

\section{The genus Leavenworthia}

Leavenworthia is a small genus of eight diploid winter annual species in the Brassicaceae, and is known to have breeding systems ranging from selfincompatible populations to highly selfing. Leavenworthia stylosa and some populations of L. crassa and L. alabamica are self-incompatible. Some populations of both L. crassa and L. alabamica are selfcompatible, with varying frequencies of selffertilization, whereas L. uniflora, L. torulosa and L. exigua are uniformly self-compatible and highly inbreeding (Lloyd, 1965; Solbrig \& Rollins, 1977). Four independent comparisons between more outcrossing and more inbreeding populations are thus possible. Two are between L. stylosa and its sister species L. uniflora and L. torulosa, in the group with $n=15$ chromosomes, another involves comparisons between different populations of $L$. crassa, in a different section of the genus having $n=11$ chromosomes, and the fourth is between different L. alabamica populations (also $n=11$ ). The natural habitat of the species is 'cedar glade' outcrops in the southeastern United States, which form about $5 \%$ of the habitat in the region where the species occurs (Quarterman, 1950), so populations are scattered and separated by unsuitable habitat (see Lloyd, 1965). Natural pollinators are nonsocial bees (but high proportions of honeybees were observed on flowers of L. crassa and L. alabamica in cultivated fields), and seeds are large and have no dispersal mechanism (Lloyd, 1965). Both pollen and seed flow between glades are therefore thought to be rare. Infrequent migration is consistent with the observations that apparently suitable habitat is often unoccupied, and that nearby glades may be occupied by different $L$. crassa races, but seeds may sometimes be transferred by streams or flooding (Lloyd, 1965).

\section{Population samples}

Population samples were studied from three populations of the $n=15$ species, L. stylosa, two populations of L. uniflora and one of L. torulosa (Table 1). From the three $n=11$ species, six populations of L. crassa, two L. alabamica populations and one of L. exigua were studied (Table 1). Some plants were collected by Dr E. E. Lyons, from populations of known breeding system (Lyons \& Antonovics, 1991), and seed from an additional population of L. stylosa was collected by $\mathrm{Dr}$ T. E. Hemmerly (Middle Tennessee State University). Other plants were collected in the field in spring 1995 with fruits already developing, and brought to the University of Chicago greenhouses where they were grown until their seeds could be collected. Plants were grown from seeds from the different populations (see Charlesworth et al., 1994), and breeding systems for populations for which this information was not already available were estimated by measuring selfincompatibility (by hand self-pollination), and/or by autogamous fruit-set in an insect-free greenhouse at the University of Chicago.

\section{Allozyme electrophoresis}

Allozyme genotypes of the greenhouse-grown plants of four of the species were determined by cellulose acetate electrophoresis (Hebert \& Beaton, 1989). 


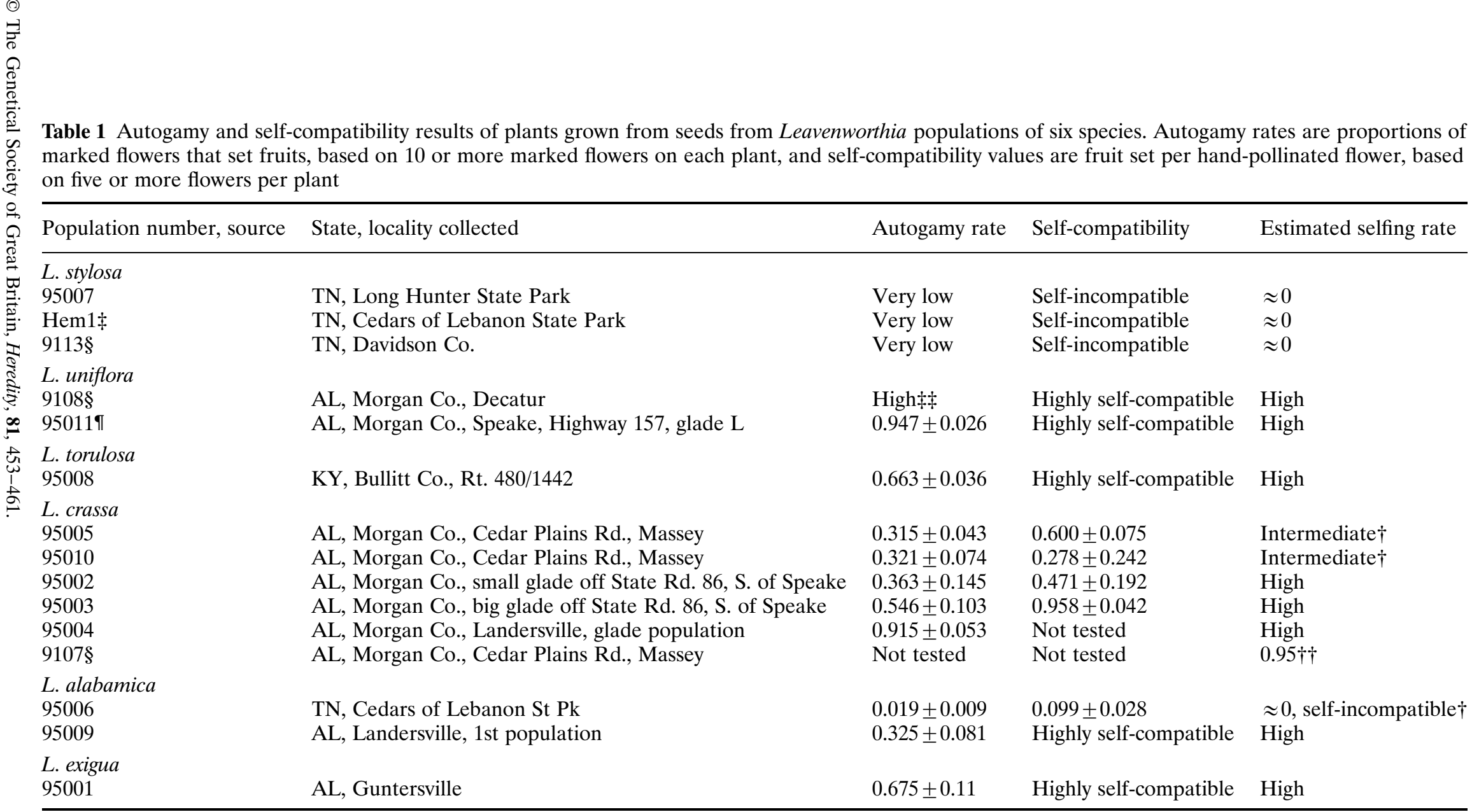

$\dagger$ Some plants self-incompatible.

$\ddagger$ Seeds supplied by Dr T.E. Hemmerly.

$\S$ Seeds supplied by Dr E.E. Lyons.

ISeeds supplied by Dr G. Hilton.

$\dagger$ †stimated by Dr E.E. Lyons (pers. comm.).

$\$$ The autogamy rate for this population was not estimated quantitatively, but was observed to be high. 
Tris-glycine buffer $\mathrm{pH} 8.5$ was used for both the polymorphic enzymes. Gels were run at $109 \mathrm{~V}$. For phosphoglucoisomerase (Pgi), runs were $15 \mathrm{~min}$, and for phosphoglucomutase (Pgm) $30 \mathrm{~min}$. Good resolution of bands was obtained only for these two enzymes. There were two Pgi systems (A, B) and three Pgm $(\mathrm{A}-\mathrm{C})$. Using pollen, which does not have plastids, it was determined that PgiA corresponds to the cytosolic Pgi (usually denoted by PgiC, see Ford et al., 1995). Other enzymes stained include acid phosphatase, glutamic-oxaloacetic transaminase, and 6-phosphogluconate, isocitrate, malate and shikimate dehydrogenases, but although variability was seen, the band patterns were not clear enough for genotypes to be scored reliably, despite testing several different buffer systems and running conditions. Starch gels were also tried, with several buffer systems, but good bands for other enzymes were not obtained. Single-locus inheritance of the Pgi and $P g m$ variants was checked by raising families from crosses between L. stylosa plants of known genotypes.

\section{Analysis}

Genotype frequencies of samples from each population were estimated from progeny plants from as many maternal plants as possible. For some populations, where the numbers of parents were small, more than one progeny per maternal plant was used. To minimize bias, four offspring per parent were grown, but a few families were smaller. This sampling is not ideal, and is likely to underestimate genetic diversity, as rare variants present in the populations may be absent from a small sample of maternal plants, but it was imposed by the small numbers of seeds that germinated from some localities. However, the main interest for the present study is in comparing genetic diversity within different populations and, with five loci studied, the sample sizes should be suitable for this purpose (Pons \& Petit, 1995). Fixation indices may, however, be inaccurately estimated, given the small samples from some of the populations studied. The alternative approach, of scoring progeny genotypes and estimating those of the maternal parents, was rejected as it does not, in general, provide reliable estimates of maternal genotypes, when the estimates are compared with genotypes known from directly scoring maternal plants (D. Charlesworth, unpubl. data). Inbreeding coefficients $(F)$ were estimated within each population using a computer program written for this purpose, and diversity values and fixation indices were estimated using FSTAT version
2.0 (Goudet, 1995). Within-population diversity was estimated as expected gene diversity $\left(H_{\mathrm{e}}\right.$, see Nei, 1987) and will be referred to here as $H_{\mathrm{S}} ; H_{\mathrm{T}}$ will be used for total species-wide diversity, which was estimated whenever more than a single population of a species was studied. Standard errors of the diversity measures are estimated in the FSTAT program by the method of Nei \& Roychoudhury (1974), and those for $G_{\mathrm{ST}}(\mathrm{Nei}, 1987)$ were estimated by jackknifing over populations.

\section{Results}

\section{Autogamy and self-fertility}

The autogamy results are summarized in Table 1 . All plants of L. stylosa were non-autogamous and self-incompatible. All L. uniflora and L. torulosa plants were highly autogamous, but these taxa differed significantly in their autogamy rates $\left(t_{18}=7.04, P<0.001\right)$. The one L. exigua population (from Guntersville, AL) has an autogamy rate of $0.675 \pm 0.11$. These results are as expected for these species (Solbrig \& Rollins, 1977). In L. crassa and L. alabamica, autogamy was variable, again as expected for these species (Lloyd, 1965). The two L. alabamica populations studied differed significantly $\left(t_{39}=5.83, P<0.001\right)$. Leavenworthia crassa showed highly significant autogamy differences, both within and between populations. Contingency table analyses of the numbers of fruits set by marked flowers gave results significant at the $P<0.0001$ level for all five populations tested, showing that individual plants varied within populations, and heterogeneity between populations was significant at the same level. Population 95004 had highly significantly higher mean autogamy than the other four populations (for the comparison with the next most autogamous population, 95003, $t_{24}=3.19, P=0.004$ ), and 95003 differed marginally significantly from the least autogamous one $95005\left(t_{63}=2.3, P=0.025\right)$ but not from populations with lesser differences in autogamy (95010 and 95002).

Self-compatibility (fruits per hand self-pollination) was estimated on a subset of the plants; in particular, non-autogamous individuals were tested for selffertility. Self-incompatible plants were found at low frequency in the L. crassa populations $95005(17 \%$ of 29 plants tested) and 95010 (21\% of 19 plants), so these populations are not merely intermediate in autogamy and selfing rates, but appear to be polymorphic for self-incompatibility. In these two populations, autogamy was highly significantly correlated with self-fertility, but there was no correlation within the other populations. Self-fertility and autogamy of 
different populations did not rank in the same order (Table 1). In L. alabamica, $63 \%$ of the 19 population 95006 plants tested were self-incompatible, whereas individuals that were self-compatible also showed some autogamy.

\section{Allozyme inheritance in L. stylosa}

Variants were seen for all five allozyme loci that could be scored. The variability will be quantified below. The inheritance of the variants was studied in a set of nine families involving seven plants, chosen because they differed at three of the loci (systems PgiB and PgmA were not variable in this set of plants). The other three loci segregated as expected given their phenotypes, assuming single-locus control of these variants. One plant was heterozygous for both the PgiC and PgmC loci, so it was possible to test for linkage between these loci (in crosses with two other plants), and linkage between $P g m B$ and $P g m C$ could be tested in two families. Despite small family sizes (average family size 17 plants), each of the four families yielded all the four possible genotypes. There is thus enough information to show that these loci are not closely linked in L. stylosa.

\section{Allozyme diversity in Leavenworthia species}

Leavenworthia stylosa was polymorphic for all five allozyme loci scored, in two of the three populations, and diversity was high (Table 2). Leavenworthia uniflora and L. torulosa could be scored for only four loci. There was no diversity within either population, but there were fixed differences between the populations for two of the loci $(\mathrm{PgiC}$ and $\mathrm{PgmC}$ ); the few plants scored from L. uniflora population 9108 were identical in genotype to those from 95011. Seeds from several L. crassa populations collected failed to germinate. The five L. crassa populations that could be studied ranged from intermediate to high autogamy. In both L. crassa and L. alabamica, four of the five loci scored were polymorphic in the species as a whole (PgiB was monomorphic), but only three individual populations of $L$. crassa were polymorphic for all four loci.

Overall, there is thus a clear relationship between high autogamy and low allozyme diversity, with L. crassa showing values intermediate between L. stylosa and the inbreeders L. uniflora and L.torulosa. Within L. crassa, the same relationship holds, with an overall statistically significant linear regression $(P<0.02)$. Population 95005, which had the

Table 2 Allozyme diversity in some Leavenworthia populations in which breeding systems have been estimated. Estimates and standard errors are given

\begin{tabular}{|c|c|c|c|c|c|c|c|c|}
\hline $\begin{array}{l}\text { Species } \\
\text { and } \\
\text { population }\end{array}$ & $\begin{array}{l}\text { Breeding } \\
\text { system }\end{array}$ & $\begin{array}{l}\text { Polymorphic } \\
\text { loci }(\%)\end{array}$ & $\begin{array}{c}\text { Mean } \\
\text { number } \\
\text { of alleles }\end{array}$ & $\begin{array}{l}\text { Number } \\
\text { of plants }\end{array}$ & $H_{\mathrm{S}}$ or $H_{\mathrm{T}}^{\dagger}$ & $F$ & $\mathrm{G}_{\mathrm{ST}}$ & $D_{\mathrm{ST}}$ \\
\hline \multicolumn{9}{|l|}{ L. stylosa } \\
\hline 95007 & SI & 80 & 3.2 & 30 & $0.372 \pm 0.331$ & 0.331 & & \\
\hline Hem1 & SI & 100 & 3.6 & 10 & $0.592 \pm 0.104$ & 0.443 & & \\
\hline 9113 & SI & 100 & 3.0 & 43 & $0.495 \pm 0.178$ & 0.648 & & \\
\hline Total for species & & 100 & - & - & $H_{\mathrm{T}}=\overline{0.524 \pm 0.240}$ & - & $0.268 \pm 0.087$ & 0.140 \\
\hline \multicolumn{9}{|l|}{ L. uniflora } \\
\hline $\begin{array}{l}\text { L. torulosa } \\
95008\end{array}$ & Inbreeder & 0 & 1.0 & 31 & 0 & - & & \\
\hline \multicolumn{9}{|l|}{ L. crassa } \\
\hline 95005 & Intermediate & 80 & 3.0 & 51 & $0.433 \pm 0.249$ & 0.571 & & \\
\hline 95010 & Inbreeder & 80 & 2.4 & 19 & $0.347 \pm 0.197$ & 0.675 & & \\
\hline 95002 & Inbreeder & 80 & 2.2 & 8 & $0.303 \pm 0.264$ & 0.531 & & \\
\hline 95003 & Inbreeder & 40 & 1.6 & 10 & $0.232 \pm 0.321$ & 0.792 & & \\
\hline 95004 & Inbreeder & 20 & 1.2 & 8 & $0.092 \pm 0.204$ & 0.709 & & \\
\hline Total for species & & 80 & - & - & $H_{\mathrm{T}}=\overline{0.424 \pm 0.266}$ & - & $0.213 \pm 0.047$ & 0.090 \\
\hline \multicolumn{9}{|l|}{ L. alabamica } \\
\hline 95006 & Mostly SI & 80 & 3.4 & 36 & $0.471 \pm 0.267$ & 0.182 & & \\
\hline 95009 & Inbreeder & 80 & 3.6 & 23 & $0.406 \pm 0.277$ & 0.699 & & \\
\hline Total for species & & 80 & - & - & $H_{\mathrm{T}}=0.561 \pm 0.322$ & - & $0.352 \pm 0.104$ & 0.197 \\
\hline
\end{tabular}

$\dagger \mathrm{H}_{\mathrm{T}}$ values are given only for species for which multiple populations were studied. 
lowest autogamy and is polymorphic for self-incompatibility, also had the highest diversity values, whereas the most autogamous population, 95004, had low diversity and fewer alleles per locus than the other populations of this species. In Fig. 1, the results from L. crassa are summarized and compared with the only other published data sets that include multiple different populations from single species. In L. alabamica, however, both the more inbreeding and the self-incompatible population had high diversity. In this species, there was also very high between-population diversity.

The allozyme data yield higher inbreeding coefficients for the more inbreeding populations than for those that are self-incompatible, as expected, but the $F$-values are high even in self-incompatible populations (observed heterozygosity was lower than the Hardy-Weinberg expectations in all populations, at least for some loci). The reason for this is uncertain, although similar values have been seen in other plant populations (Brown, 1979). Null alleles are one possibility. No evidence for null homozygotes was seen in data found by the present study, but the number of parents involved in the study crosses was not large, and as the species used in the genetic tests is self-incompatible there were no progeny from selfing, so null alleles might remain undetected. Local differentiation in allele frequencies is another possibility (Ennos \& Clegg, 1982), but is unlikely as frequencies would have to be very different in

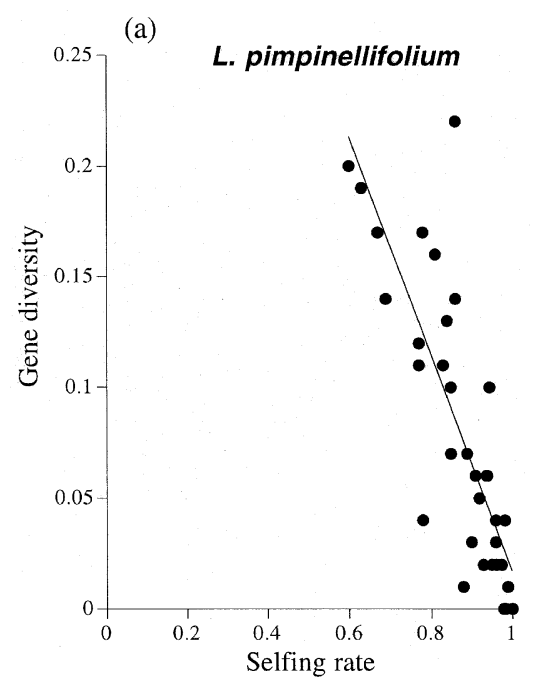

different subpopulations. Allele frequencies differ substantially between different populations of the same species, as reflected in the quite large values of $D_{\text {ST }}$, but these differences are over distances of many $\mathrm{km}$. Given the high $F$-values, it is clearly not worthwhile to attempt to estimate the selfing rate, $S$, of the populations, using the well-known relationship $F=S /(2-S)$ (Haldane, 1924). Overall, however, there is a relationship with the levels of inbreeding, as assessed by autogamy and self-compatibility. In L. alabamica $F$ is much higher for the inbreeding than the self-incompatible population. In the set of moderately to highly inbreeding $L$. crassa populations, the same trend is seen (Fig. 1), but is not statistically significant. $G_{\mathrm{ST}}$ for the outcrossing $L$. stylosa (0.268, with $95 \%$ confidence interval 0.156-0.481) was low, but cannot be compared with results for inbreeders, as only single populations of L. uniflora and L. torulosa were studied, and, for L. crassa, only one partially outcrossing population was surveyed, because of poor germination of seeds from most outcrossing populations.

\section{Discussion}

These results support earlier findings showing extreme selfing rate differences in Leavenworthia, even between different populations of L. crassa or L. alabamica (Lloyd, 1965). All the evidence is consistent in showing that L. stylosa and some popu-

Fig. 1 The relationship between allozyme diversity and levels of inbreeding in three species. (a) Selfing rates and gene diversity values for different populations of Lycopersicon pimpinellifolium (re-analysis of data in Rick et al., 1977); (b) selfing rates and gene diversity values for different populations of Eichhornia paniculata (unpubl. data from the same populations as in Barrett \& Husband, 1990); (c) gene diversity values and inbreeding coefficients in relation to autogamy rates in Leavenworthia crassa. 
lations of L. crassa and L. alabamica are highly outcrossing, whereas other populations of L. crassa and L. alabamica are inbreeders, as are L. uniflora, L. torulosa and L. exigua. Autogamy measured in the greenhouse is very variable from year to year (Lloyd, 1965), presumably because of environmental differences, but the clear correlations with self-fertility measurements show that real differences exist between plants within populations, and between different Leavenworthia species. Self-fertility and autogamy of $L$. crassa populations did not rank in the same order, showing that autogamy is not an inevitable consequence of self-fertility.

The allozyme electrophoresis results also support these conclusions and agree with those of Solbrig (1972), who showed that band variability is higher in outbreeding than inbred Leavenworthia populations, but did not quantify allozyme diversity, and Lyons \& Antonovics (1991), who found a higher frequency of polymorphic loci in inbreeding than outbreeding populations of L. crassa. Although the rankings of autogamy and gene diversity do not agree perfectly in the data from L. crassa, the only deviation from such agreement is the reversed order of the two most autogamous populations, both with low diversity. In L. alabamica, however, both populations had high diversity, even though one population (95009) is clearly more self-compatible and more autogamous than the other (95006), and has a higher inbreeding coefficient. No consistent effect of breeding system was seen on between-population differentiation.

The results are thus also consistent with the patterns of allozyme diversity seen generally in inbreeding and outcrossing plants. Overall, withinpopulation allozyme diversity in inbreeders averages about half that of outcrossers (e.g. Schoen \& Brown, 1991; Hamrick \& Godt, 1996), but a greater proportion of the diversity of selfing plants is between populations. $G_{\text {ST }}$ values for inbreeding and outcrossing dicotyledonous plants average 0.587 and 0.184 , respectively, and breeding system is a major factor influencing $G_{\mathrm{ST}}$ and $F_{\mathrm{ST}}$ values of plant species (Hamrick \& Godt, 1996). The few within-genus comparisons available give similar results, although selfers often have less than half the within-population diversity of related outcrossers (Fenster \& Ritland, 1992; Wyatt et al., 1992; Charlesworth et al., 1997) and they appear also to show lower total diversity. These results also agree well with those reviewed in the past for morphological and quantitative genetic diversity, as well as diversity for genetic markers (Baker, 1953; Brown, 1979). Much of the $G_{\mathrm{ST}}$ difference could be explained by the lower within-population diversity in inbreeding species (0.165 for dicotyledonous selfers vs. 0.091 for outcrossers, see Hamrick \& Godt, 1996); differences in $D_{\mathrm{ST}}$ are less pronounced, although there is still a tendency for inbreeders to have higher values (Charlesworth et al., 1997).

The reasons for lower within-population diversity in inbreeding compared with outbreeding populations are not yet fully understood, and it is difficult to discriminate between the different possibilities outlined above. Comparing L. stylosa with its inbreeding relatives L. uniflora and L. torulosa, the effect of loss of self-incompatibility on allozyme diversity (measured as gene diversity) is clearly greater than twofold (but the effect of inbreeding on total species allozyme diversity is not known, because only single populations of the inbreeding species were studied). In L. crassa, the most inbreeding population averaged about $21 \%$ of the diversity values of the most outcrossing population studied here, the diversity of which was only slightly lower than the average $H_{\mathrm{S}}$ value of the three L. stylosa populations (0.486). Given that the most highly outcrossing L. crassa populations studied here are moderately inbreeding, this again suggests a considerably more than twofold effect for the diversity difference between highly inbred and outcrossing populations. These results are in agreement with data from the few other comparisons between closely related populations (Rick et al., 1977; Barrett \& Husband, 1990; Fenster \& Ritland, 1992); all these studies find an effect of inbreeding greater than that estimated from comparisons of unrelated species (Hamrick \& Godt, 1996). This large effect argues for an effect of inbreeding on neutral diversity additional to the direct effect of homozygosity on effective population size.

Hitch-hiking events (selective sweeps) are a possible cause of low allozyme diversity in inbreeders, but do not seem likely to explain the data obtained by the present study. When populations lose self-incompatibility and evolve selfing, spread of alleles causing increased selfing must have occurred, and selective sweeps would have been possible during this process. Yet, in both L crassa and L. alabamica, there is considerable allozyme diversity within inbreeding populations. There must therefore have been enough outcrossing during the spread of the alleles causing selfing to allow recombination to occur between heterozygous genomes, and sufficient time for these exchanges to make the allozyme loci independent of the locus or loci that control the breeding system difference. This is quite plausible, given that neither of these taxa includes extremely 
inbreeding populations, and very high inbreeding is needed for large effects of selective sweeps (Hedrick, 1980). Even in L. uniflora and L. torulosa, there is probably enough outcrossing for selective sweeps to be unlikely to explain their complete lack of diversity.

Another possible explanation for the presence of diversity in L. crassa and L. alabamica is that some form of balancing selection maintains allozyme diversity, even in highly inbreeding populations. Because polymorphisms maintained by overdominance are expected to be lost under sufficiently high inbreeding (Kimura \& Ohta, 1971), some other form of selection may be involved. Alternatively, given the complete absence of allozyme diversity within L. uniflora and L. torulosa populations, these species (but not the inbreeding populations of L. crassa and L. alabamica) may exceed the threshold inbreeding level at which the polymorphisms are lost.

Highly inbreeding populations are also expected to evolve reduced diversity because of background selection (Charlesworth et al., 1993). Under this hypothesis, the non-negligible allozyme diversity in some present-day inbreeding populations is explicable in terms of recent evolution of selfing, because equilibrium levels of genetic diversity will not be established until many generations have passed under a changed breeding system. As both L. crassa and L. alabamica are polymorphic for self-incompatibility (see above), a recent origin is probable.

To gain further insight into the causes of low genetic diversity of inbreeders, it will be very helpful to have data on DNA sequence variability from several loci. DNA sequence analysis can provide data on silent variants, such as synonymous and intron sites in loci, which are probably close to neutral. It will be important to know whether similar patterns of low diversity in inbreeders are seen for neutral variants. If allozymes and DNA variants are not concordant, this might support the suggestion that the allozyme diversity is maintained by balancing selection. Furthermore, even assuming selective neutrality, differences between genotypes for allozymes probably do not increase linearly with genealogical times (Marshall \& Brown, 1975), and cannot therefore be used in tests, such as Tajima's test (Tajima, 1989), which can detect events such as selective sweeps that affect diversity, and may thus be able to reveal the causes of any differences found.

Although some sequence diversity estimates exist for plant populations that have also been studied for their allozyme diversity (mostly from RFLP studies, e.g. Zhang et al., 1993; Raybould et al., 1996), the diversity is not often expressed in terms of comparable measures such as estimated diversity per site. There are, moreover, as yet no quantitative comparisons of sequence diversity involving populations with different inbreeding levels, although a general concordance between the two kinds of data, with low diversity in inbreeding species, has been established in Lycopersicon (Miller \& Tanksley, 1990). Some preliminary data show a large difference between inbreeding and outcrossing Leavenworthia populations, and no diversity within inbreeding populations of L. uniflora and L. crassa, at least at some loci (Liu et al., 1998). For L.crassa, this contrasts with the allozyme data presented here.

\section{Acknow ledgements}

We thank Drs T. E. Hemmerly, E. E. Lyons and G. Hilton for seed collections, the staff of the University of Chicago greenhouses for plant care, J. Goudet for sending the beta version of FSTAT 2.0 for Windows, P. Awadalla for performing the FSTAT analyses, S. C. H. Barrett and B. C. Husband for providing unpublished data, and B. Charlesworth for discussions. This work was supported by grant GM50355 from the National Institutes of Health, USA.

\section{References}

BAKER, H. G. 1953. Race formation and reproductive method in flowering plants. SEB Symposia, 7, 114-145.

BARRETT, s. C. H. AND HUSBAND, B. C. 1990. Variation in outcrossing rates in Eichhornia paniculata: the role of demographic and reproductive factors. Pl. Sp. Biol., 5, 41-55.

BEGUN, D. J. AND AQUADRO, C. F. 1992. Levels of naturally occurring DNA polymorphism correlate with recombination rates in D. melanogaster. Nature, 356, 519-520.

BRown, A. H. D. 1979. Enzyme polymorphism in plant populations. Theor. Pop. Biol., 15, 1-42.

CHARLESWORTH, B., MORGAN, M. T. AND CHARLESWORTH, D. 1993. The effect of deleterious mutations on neutral molecular variation. Genetics, 134, 1289-1303.

CHARLESWORTH, B., NORDBORG, M. AND CHARLESWORTH, D. 1997. The effects of local selection, balanced polymorphism and background selection on equilibrium patterns of genetic diversity in subdivided populations. Genet. Res., 70, 155-174.

CHARLESWORTH, D., LYONS, E. E. AND LITCHFIELD, L. B. 1994. Inbreeding depression in two highly inbreeding populations of Leavenworthia. Proc. R. Soc. B, 258, 209-214.

ENNOS, R. A. AND CLEGG, M. T. 1982. Effect of population substructuring on estimates of outcrossing rate in plant populations. Heredity, 48, 283-292.

(c) The Genetical Society of Great Britain, Heredity, 81, 453-461. 
FENSTER, C. B. AND RITLAND, K. 1992. Chloroplast DNA and isozyme diversity in two Mimulus species (Scrophulariaceae) with contrasting mating systems. Am. J. Bot., 79, 1440-1447.

FORD, V. S., THOMAS, B. R. AND GOTTLieb, L. D. 1995. The same duplication accounts for the PgiC genes in Clarkia xantiana and C. lewisii (Onagraceae). Syst. Bot., 20, $147-160$

GOUDET, J. 1995. Fstat v-1.2: a computer program to calculate F-statistics. J. Hered., 86, 485-486.

HALDANE, J. B. S. 1924. A mathematical theory of natural and artificial selection. II. The influence of partial self fertilisation, inbreeding, assortative mating and selective fertilisation on the composition of Mendelian populations and on natural selection. Proc. Camb. Phil. Soc., 1, 158-163.

HAMRICK, J. L. AND GODT, M. J. w. 1996. Effects of life history traits on genetic diversity in plant species. Phil. Trans. R. Soc. B, 351, 1291-1298.

HEBERT, P. D. N. AND BEATON, M. J. 1989. A Practical Handbook of Cellulose Acetate Electrophoresis. Helena Laboratories, Beaumont, TX.

HEDRICK, P. W. 1980. Hitch-hiking: a comparison of linkage and partial selfing. Genetics, 94, 791-808.

HUDSON, R. R., BAILEY, K., SKERECKY, D., KWIATOWSKI, J. AND AYALA, F. J. 1994. Evidence for positive selection in the superoxide dismutase (Sod) region of Drosophila melanogaster. Genetics, 136, 1329-1340.

JARNE, P. AND STAEDLER, T. 1995. Population genetic structure and mating system in freshwater pulmonates. Experientia, 51, 482-497.

KARL, S. A. AND AVISE, J. C. 1992. Balancing selection at allozyme loci in oysters: implications from nuclear RFLPs. Science, 256, 100-102.

KIMURA, M. 1983. The Neutral Theory of Molecular Evolution. Cambridge University Press, Cambridge.

Kimura, M. And ohta, T. 1971. Theoretical Topics in Population Genetics. Princeton University Press, Princeton, NJ.

KREITMAN, M. 1991. Detecting selection at the level of DNA. In: Selander, R. K., Clark, A. G. and Whitham, T. S. (eds) Evolution at the Molecular Level, pp. 204-221. Sinauer Associates, Sunderland, MA.

LANGley, C. H. 1990. The molecular genetics of Drosophila. In: Takahata, N. and Crow, J.F. (eds) Population Biology of Genes and Molecules, pp. 75-91. Baifukan, Tokyo.

LiU, F., ZHANG, L. AND CHARlesworth, D. 1998. Genetic diversity in Leavenworthia populations with different inbreeding levels. Proc. R. Soc. B, 265, 293-301.

LLOYD, D. G. 1965. Evolution of self-compatibility and racial differentiation in Leavenworthia (Cruciferae). Contr. Gray Herb., 195, 3-134.

LYONS, E. E. AND ANTONOVICS, J. 1991. Breeding system evolution in Leavenworthia: breeding system variation and reproductive success in natural populations of
Leavenworthia crassa (Cruciferae). Am. J. Bot., 78, 270-287.

MARSHALL, D. R. AND BROWN, A. H. D. 1975. The charge state model of protein polymorphisms in natural populations. J. Mol. Evol., 6, 149-163.

MILLER, J. C. AND TANKSLEY, S. D. 1990. RFLP analysis of phylogenetic relationships and genetic variation in the genus Lycopersicon. Theor. Appl. Genet., 80, 437-448.

NEI, M. 1987. Molecular Evolutionary Genetics. Columbia University Press, New York.

NEI, M. AND ROYCHOUdHury, A. K. 1974. Sampling variances of heterozygosity and genetic distance. Genetics, 76, 379-390.

POGSON, G. H. AND zouros, E. 1994. Allozyme and RFLP heterozygosities as correlates of growth rate in the scallop Placopecten magellanicus: a test of the associative overdominance hypothesis disequilibrium. Genetics, 137, 221-231.

POLLAK, E. 1987. On the theory of partially inbreeding finite populations. I. Partial selfing. Genetics, 117, $353-360$.

PONS, O. AND PETIT, R. J. 1995. Estimation, variance and optimal sampling of gene diversity. I. Haploid locus. Theor. Appl. Genet., 90, 462-470.

QUARTERMAN, E. 1950. Major plant communities of Tennessee cedar glades. J. Ecol., 31, 234-254.

RAYBOUld, A. F., MOGG, R. J. AND ClARKE, R. T. 1996. The genetic structure of Beta vulgaris ssp. maritima (sea beet) populations: RFLPs and isozymes show different patterns of gene flow. Heredity, 77, 245-250.

RICK, C. M., FOBES, J. F. AND HOLLE, M. 1977. Genetic variation in Lycopersicon pimpinellifolium: evidence of evolutionary change in mating systems. Pl. Syst. Evol., 127, 139-170.

SCHOEN, D. J. AND BROWN, A. H. D. 1991. Intraspecific variation in population gene diversity and effective population size correlates with the mating system in plants. Proc. Natl. Acad. Sci. U.S.A., 88, 4494-4497.

SOLBRIG, O. T. 1972. Breeding system and genetic variation in Leavenworthia. Evolution, 26, 155-160.

SOLBRIG, O. T. AND ROLlins, R. C. 1977. The evolution of autogamy in species of the mustard genus Leavenworthia. Evolution, 31, 265-281.

TAJIMA, F. 1989. Statistical method for testing the neutral mutation hypothesis. Genetics, 123, 585-595.

wOLFF, K. 1991. Analysis of allozyme variability in three Plantago species and a comparison to morphological variability. Theor. Appl. Genet., 81, 119-126.

WyATt, R., EVANS, E. A. AND SORENSON, J. C. 1992. The evolution of self-pollination in granite outcrop species of Arenaria (Caryophyllaceae). VI. Electrophoretically detectable genetic variation. Syst. Bot., 17, 201-209.

ZHANG, Q., SAGHAI-MAROOF, M. A. AND KLEINHOFS, A. 1993. Comparative diversity analysis of RFLPs and isozymes within and among populations of Hordeum vulgare ssp. spontaneum. Genetics, 134, 909-916. 